\title{
The Use of Transition Signals in University Students' Community Service Report
}

\author{
Ni Putu Cahyani Putri Utami \\ Fakultas Bahasa Asing, Universitas Mahasaraswati Denpasar \\ cahyaniputri253@gmail.com \\ Made Wahyu Mahendra \\ Universitas Hindu Negeri I Gusti Bagus Sugriwa \\ madewahyumahendra@uhnsugriwa.ac.id
}

\begin{abstract}
Transition signals are the essential elements to achieve a well-structured text. The ideas in the text need to connect to each other. It will be difficult for the reader to understand the sequence if the ideas are simply just exposed by the writer without being related to each other. Students' competency and ability in English academic writing overviewed from their competence in constructing sentences. Therefore, this research aimed to find out the use of transition signals and their accuracy in students' community service report. The research used a descriptive quantitative method. The data were taken from students' community service report written by the seventh semester English literature students of Foreign Languages Study Program of Universitas Mahasaraswati Denpasar. The finding of this research showed that the total number of transition signals used by the students in their community service report were 303 and classified into eight types of transition signals. Transition signals to introduce sequence and logically order ideas was mostly used and transition signals to emphasize ideas was least used by the students. From the whole types of transition signals, the average usage accuracy was above $60 \%$.
\end{abstract}

Keywords: transition signals, academic writing

\section{Introduction}

Academic writing becomes one of the essential elements to take concern for students who learn English as a foreign language, particularly for university students in Indonesia, for academic writing purposes, such as essays, papers, project reports, articles, journal writings, and theses. Since writing has a vital role that is used for global mediation of knowledge, being competent in writing is much needed for EFL university students to complete their study (Fareed, Ashraf \& Bilal, 2016). However, Brown

(2004) stated writing is the most complicated skill among the other language skills because there are several components that need to be mastered by the students. For many EFL university students in Indonesia, academic writing might be very complex compared to creative writing. Since English is not their first language, there might be some mistakes made by them. Moreover, for most university students in Indonesia, who come from nonAnglicized linguistic and literature background, writing in academic English is a difficult and challenging 
task. The difficulty is not only in delivering their ideas but also organizing their ideas into a wellstructured text.

Brown (2004) explained that there are five main components that must be mastered by students to produce a well-structured text; they are spelling, grammar, punctuation, coherence, and organization of ideas. Organizing ideas becomes the most difficult component to be mastered because a text can be called good writing if the ideas are well organized and build a united form within paragraphs. Abu-Ghararah \& Hamzah (1998) described academic writing as a complex logical organization and arrangement sentences within paragraphs and the units of discourses. If the ideas are simply just exposed without being connected and related to one another, it will be difficult for the reader to understand the sequence of the writing. Therefore, the students need to give attention to the organization of their ideas in the writing academic English process.

By knowing about the organizational structure of academic writing, the students should give extra attention to not only its organization of their writing but also to its coherence. Oshima \& Hogue (1997) explained a coherent paragraph in a text flows smoothly from the beginning to the end of the text by using references, transition signals to show relationships among ideas and set the ideas in order logically. Focusing on academic writing, students' competency, and ability in writing academically commonly overviewed from their competence in constructing sentences. There are several things that they should notice; one of them is the use of transition signals.

Stott (1991) mentioned that transition signals are words or phrases that link one sentence or paragraph to another and without the use of them, the paragraphs appear disorganized. Transition signals are used to make the movement of the paragraphs in the text logical and smooth. Besides, a transition signal could strengthen the internal cohesion and coherence in a text. It shows the relationship between the parts of sentences in a paragraph or between paragraphs because it provides a valuable signal to the reader about the relationship between parts of the text. As a result, good academic writing requires appropriate transition signals usage by university students to achieve good academic writing.

Several studies regarding difficulties faced by Indonesian university students in using transition signals accurately have been conducted. Rachmawati \& Susanti (2016) found that most EFL students felt difficult to use certain transition signals in an appropriate and correct way. As well Annurrahman, Hamied \& Emilia (2016) found that the EFL students' writing in Pontianak, West Kalimantan found difficulties in writing an argumentative essay. They showed a lack of discourse competency due to their 
argumentative essay was still limited, especially in developing their critical thinking in their essay and organizing their essay.

Ariyanti \& Fitriana (2017) found that Indonesian EFL university students in Samarinda, East Kalimantan had misused the use of cohesive and coherence devices in a text. Mahendra (2017) further explained that students were stuck when they described the setting and the background of their text. Moreover, the students had difficulties with the organization of ideas and paragraphs, grammar accuracy, and lack of vocabulary mastery. This problematic issue has become a principal issue for university students since they are required to write academically in English. Therefore, the present study in many universities in Indonesia aimed to develop students' writing skills by giving them a chance to practice.

The students in university are suggested to start their writing practice intensively since in their first semester, so they would have much time to practice and develop their writing skills. The writing components should be introduced to the students in every stage of the teaching and learning process because they are not considered to be mastered in a short period of time. In accordance with the background, this study interested in finding out the use of transition signals and their accuracy in students' academic writing written by the seventh semester English literature students of the Faculty of Foreign Languages of Universitas Mahasaraswati Denpasar.

\section{Research Method}

The data which described in these findings of the research were taken from Community Service Program (community service) report written by the seventh semester English literature students of Faculty of Foreign Languages of Universitas Mahasaraswati Denpasar. They were students who carried out their community service program. The report made by Group 14 which consisted of 16 male students and 9 female students. The community service report was constructed by students according to their ability in using transition signals in their academic writing. This study aimed to find out the types and their accuracy of transition signals used by the students in their community service report.

Documentation method used to collect the data source in the form of academic writing. The data were collected without any intervention from the researcher. In collecting the data, the researcher focused on the types and the accuracy of transition signals which were used by the students in their community service report. The researcher identified and classified the transitional signals used by the students in their academic writing based on their types in the form of a table. The data were classified based on the theory from Oshima \& Hogue (1998). Library research was conducted to enhance 
the theory and information about transition signals from several studies and experts.

The variable and sub variables of this research were transition signals which included: 1) transition signals to introduce an additional idea, 2) transition signals for showing cause and effect, 3) transition signals for showing contrast, 4) transition signals for showing comparison, 5) transition signals to provide example, 6) transition signals to emphasize ideas, 7) transition signals to conclude or summarize and 8) transition signals to introduce sequence and logically order ideas. The next step was calculated the frequency and percentage of the usage on each type of transition signal. The formula which was used to calculate the percentage of frequency and accuracy of the transition signals as follows: $P=\frac{F}{N} \times 100$

\section{Finding \& Discussion}

The analysis of the use of transition signals students community service report based on the types of transition signals theory which proposed by Oshima \& Hogue (1998). In collecting the data, the transition signals which are used by the students in their community service report were identified, and then classified them into eight types of transition signals based on the theory. Finally, the data were listed generally in the table based on its type. The classification can be seen in the Table 1 below.

Table 1. The Classification of Transition Signals Used by Students in Community Service Report

\begin{tabular}{|l|l|c|c|}
\hline \multicolumn{1}{|c|}{$\begin{array}{c}\text { Types of } \\
\text { Transition } \\
\text { Signals }\end{array}$} & $\begin{array}{c}\text { Form of Transition Signals } \\
\text { Used in Students' Community } \\
\text { Service Report }\end{array}$ & Frequency & $\begin{array}{c}\text { Percentage } \\
\text { (\%) }\end{array}$ \\
\hline $\begin{array}{l}\text { Transition } \\
\text { signals to } \\
\text { introduce an } \\
\text { additional idea }\end{array}$ & $\begin{array}{l}\text { in other words, besides, } \\
\text { furthermore, as well as, in } \\
\text { addition, moreover, and, in fact }\end{array}$ & 60 & $20 \%$ \\
\hline $\begin{array}{l}\text { Transition } \\
\text { signals for } \\
\text { showing cause } \\
\text { and effect }\end{array}$ & $\begin{array}{l}\text { so, therefore, because, since, } \\
\text { because, as, } \\
\text { because of, due to, as a result, } \\
\text { thus, for, }\end{array}$ & 25 & $8 \%$ \\
\hline $\begin{array}{l}\text { Transition } \\
\text { signals for } \\
\text { showing } \\
\text { contrast }\end{array}$ & $\begin{array}{l}\text { in contrast, unlike, yet, on the } \\
\text { contrary, on the other hand, } \\
\text { however, while, whereas, however, } \\
\text { although, unlike }\end{array}$ & 15 & $5 \%$ \\
\hline $\begin{array}{l}\text { Transition } \\
\text { signals for }\end{array}$ & $\begin{array}{l}\text { or, if, as well as, similarly to, } \\
\text { otherwise, }\end{array}$ & 36 & $12 \%$ \\
\hline
\end{tabular}




\begin{tabular}{|l|l|c|c|}
\hline $\begin{array}{l}\text { showing } \\
\text { comparison }\end{array}$ & $\begin{array}{l}\text { likely to, compared to, in the same } \\
\text { way (with), likewise }\end{array}$ & 29 & $10 \%$ \\
\hline $\begin{array}{l}\text { Transition } \\
\text { signals to } \\
\text { provide } \\
\text { example }\end{array}$ & $\begin{array}{l}\text { for example, for instance, such as, } \\
\text { namely, } \\
\text { to illustrate }\end{array}$ & 6 & $2 \%$ \\
\hline $\begin{array}{l}\text { Transition } \\
\text { signals to } \\
\text { emphasize } \\
\text { ideas }\end{array}$ & especially, in fact, above all \\
\hline $\begin{array}{l}\text { Transition } \\
\text { signals to } \\
\text { conclude or } \\
\text { summarize }\end{array}$ & $\begin{array}{l}\text { in conclusion, it can be concluded } \\
\text { that, } \\
\text { to summarize, thus, to conclude }\end{array}$ & 40 & $13 \%$ \\
\hline $\begin{array}{l}\text { Transition } \\
\text { signals to } \\
\text { introduce } \\
\text { sequence and } \\
\text { logically order } \\
\text { ideas }\end{array}$ & $\begin{array}{l}\text { at this point, previously, during, } \\
\text { formerly, last, then, before, first, } \\
\text { second, third, last, then, firstly, } \\
\text { secondly, next, at first, lastly }\end{array}$ & 92 & $30 \%$ \\
\hline
\end{tabular}

Data in Table 1 showed that there are eight types and several forms of transitional signals used by seventh semester students in their community service report. The types and the forms of transition signals in details were; (1) Transition signals to introduce an additional idea, such as in other words, besides, furthermore, as well as, in addition, moreover, and, in fact; (2) Transition signals for showing cause and effect, such as so, therefore, because, since, because, as, because of, due to, as a result, thus, for, for this reason; (3) Transition signals for showing contrast, such as in contrast, unlike, yet, on the contrary, on the other hand, however, while, whereas, however, although, unlike; (4) Transition signals for showing comparison, such as or, if, as well as, similarly to, otherwise, compared to, in the same way (with), likely to, likewise; (5) Transition signals to provide example, such as for example, for instance, such as, namely, to illustrate; (6) Transition signals to emphasize ideas, such as especially, in fact, above all; (7) Transition signals to conclude or summarize, such as in conclusion, it can be concluded that, to summarize, thus, to conclude and (8) Transition signals to introduce sequence and logically order ideas, such as at this point, previously, during, formerly, last, then, before, first, second, third, last, then, firstly, secondly, next, at first, lastly.

After finding the types and the forms of the transition signals used by the students in their community service report, the researcher 
calculated the frequency and the percentage of each type which has been used by the students' academic writing. This calculation done to find out which type of transition signal mostly used by the students. Table 1 above showed that the total of transition signals produced by students in their academic writing are 303 and it classified into eight types of transition signals. Based on the data, the use of transition signals to introduce sequence and logically order ideas was mostly used by the students in their community service report (92 times). Meanwhile, the transition signals to emphasize ideas was least used by the students (6 times).

Based on Table 1, the percentage of the frequency of the transition signals that mostly used was $92 \%$ and the percentage which the least used was $2 \%$. Based on the research, it was clearly that students wanted to create powerful links between sentences and paragraphs to connect the ideas and information which they presented in their community service report and achieve cohesion. Haliday \& Hasan (1976) explained that a text is cohesive when the elements are tied together and considered meaningful to the reader. Moreover, cohesion occurred when the interpretation of one item depends on the other (Halliday \& Hasan, 1976). In conclusion, transition signals structure the text in a certain logical order that is meaningful to the reader.

It is necessary to logically order ideas to achieve a good and well-structured text since the goal of the writing is to convey information clearly and concisely to the reader. Transition signals in writing are vital devices which carry the ideas of the writer to the reader from one idea to another. A good and well-structured text requires to use transition signals correctly. It is emphasized by Provost (1998) that the use of transition signals in a text should be accurate, short, direct, and almost invisible. Oshima \& Hogue (1998: 44-45) divided transition signals into three groups based on their grammatical function; they are: sentence connectors, clause connectors, and mixed group called other. Furthermore, those transition signals can be put in the beginning of a sentence, in the middle of the sentence or it can be appeared at the end of the sentence. 
Table 2. The Accuracy of Transition Signals in Students' Community Service Report

\begin{tabular}{|c|c|c|c|}
\hline Types of Transition Signals & $\begin{array}{l}\text { Frequency of } \\
\text { Transition } \\
\text { Signals }\end{array}$ & $\begin{array}{c}\text { Frequency } \\
\text { Correct } \\
\text { Transition } \\
\text { Signals }\end{array}$ & $\begin{array}{c}\text { Percentage } \\
(\%)\end{array}$ \\
\hline $\begin{array}{l}\text { Transition signals to } \\
\text { introduce an additional idea }\end{array}$ & 60 & 53 & $88 \%$ \\
\hline $\begin{array}{l}\text { Transition signals for } \\
\text { showing cause and effect }\end{array}$ & 25 & 20 & $80 \%$ \\
\hline $\begin{array}{l}\text { Transition signals for } \\
\text { showing contrast }\end{array}$ & 15 & 12 & $80 \%$ \\
\hline $\begin{array}{l}\text { Transition signals for } \\
\text { showing comparison }\end{array}$ & 36 & 33 & $91 \%$ \\
\hline $\begin{array}{l}\text { Transition signals to } \\
\text { provide example }\end{array}$ & 29 & 22 & $76 \%$ \\
\hline $\begin{array}{l}\text { Transition signals to } \\
\text { emphasize ideas }\end{array}$ & 6 & 4 & $67 \%$ \\
\hline $\begin{array}{l}\text { Transition signals to } \\
\text { conclude or summarize }\end{array}$ & 40 & 34 & $85 \%$ \\
\hline $\begin{array}{l}\text { Transition signals to } \\
\text { introduce sequence and } \\
\text { logically order ideas }\end{array}$ & 92 & 87 & $95 \%$ \\
\hline Total & 303 & 265 & $87 \%$ \\
\hline
\end{tabular}

Table 2 showed that most of the seventh students of English literature on Faculty of Foreign Languages of Universitas Mahasaraswati Denpasar who have been finished their community service program and wrote their community service report were good in using transition signals. The total percentage of the accuracy of transition signals that have been used by the students in their final report was $87 \%$. There were 303 transition signals in total used by the students in their community service report, and 265 transition signals were correctly used by the students. In addition, the percentage of the accuracy for each type of transition signals used by the students were above $60 \%$.

First, the highest percentage of the accuracy of the use of transition signals to introduce sequence and logically order ideas was 95\%. From 92 transition signals to introduce sequence and logically order ideas which were used by the students, 87 transition signals were correctly used by the students. Secondly, the use or transition signals for showing comparison was $91 \%$ correctly used. From 36 transition signals for showing comparison, 33 transition signals were properly used by the students. In other words, only 3 
transition signals were incorrectly used. Meanwhile, there was a decline from the percentage accuracy in emphasizing ideas. The percentage of accuracy for emphasizing ideas was $67 \%$, because there were only 4 out of 6 transition signals for emphasizing ideas were accurately used by the students in their community service report.

The use of transition signals in every writing would be vary. The diverse use of the transition signals determined by several aspects. According to Ampa, Akib, \& Sari (2019) the different usage of transition signals determined by the genre of the text, if the genre of the text is concerned with the historical event, then the time of sequence type will have high probability to be appeared in the text. In the same way, if the genre of the text is concerning to the facts, certainly the type of transitional signals that will appear more is transition signals to indicate cause and effect. Therefore, the use of transition signals depends on the genre of the text.

Secondly, students' knowledge of transition signals becomes another aspect of the diverse use of transition signals. Mahendra \& Dewi (2017) found that the students in university tend to overuse some transitional signals in their writing, such as however and in fact or moreover and also. This led to sentence confusion to the reader because they contained two different indication. Ampa, Akib, \& Sari (2019) further explained that students need to be familiar with the types of transition signals, so they can use them accurately in writing academic English. Thus, the present study in many universities in Indonesia indicates to the ability of students writing skill becoming a principal issue. Students in university are suggested to do a small project, such as writing an article, make an essay or other kind of academic writing project since in their first semester of their study.

\section{Conclusion}

Based on the research, the total number of transition signals used by the students in their community service report were 303 and it classified into eight types of transition signals. The use of transition signals to introduce sequence and logically order ideas was mostly used by the students in their community service report. Meanwhile, the transition signals to emphasize ideas was least used by the students. In details, there were 92 transitional signals to introduce sequence and logically order ideas, 60 transition signals to introduce an additional idea, 40 transition signals to conclude or summarize, 36 transition signals for showing comparison, 29 transition signals to provide example, 25 transition signals for showing cause and effect, 15 transition signals for showing contrast and 6 transition signals to emphasize ideas. Moreover, from the whole types of transition signals used by the students in their community service report, the highest percentage of the accuracy of the use of transition signals to introduce sequence and 
logically order ideas was 95\%. On the contrary, transition signals for emphasizing ideas were $67 \%$ accurately used by the students. It can be concluded that the students' ability in using transition signals in their academic writing was good because the percentage of the accuracy for each type of transition signals used by the students were above $60 \%$.

\section{References}

Abu-Ghararah \& Hamzah, A. (1998). Teaching English as a Foreign Language: Procedure, Techniques and Activities. Riyadh: Tawbah Library

Ampa, A.T., Akib, E. \& Sari, D.K. (2019). The Use of Transitional Signals in Essay by EFL Students. International Journal of English Language $\mathcal{E}$ Translation Studies. Vol. 7 (2). 33-38

Annurrahman, Hamied, F.A., \& Emilia, E. (2016). Exploring an Academic Writing Class in an Indonesian University Context. Language Circle: Journal of Language and Literature 11 (1), 1-12. DOI: 10.15294/lc.v11i1.7842

Ariyanti, A. \& Fitriana, R. (2017). EFL Students' Difficulties amd Needs in Essay Writing. Advances in Social Science, Education and Humanities Research (ASSEHR), 158, 111121

Brown, H.D. 2004. Language Assessment Principle and
Classroom Practice. New York: Longman

Fareed, M., Ashraf, A., \& Bilal M. (2016). ESL Learners' Writing Skills: Problems, Factors, and Suggestions. Journal of Education and Social Sciences. 4 81-92. DOI: 10.20547/jess0421604201

Halliday, M.A.K. \& Hasan, R. (1976). Cohesion in English. London: Longman

Mahendra, M.W \& Dewi, N.P. (2017). The Use of Transition Signals in EFL Academic Writing Context: A Corpus Study. Jurnal Bahasa Lingua Scientia. 9 (1), 87-89. 10.21274/1s.2017.9.1.87-100

Mahendra, M.W. (2017). Realizing Learners' Writing Problem from the Beginning: A Case Study. Journal of English Language, Literature, and Teaching. 2 (1), 1-8. DOI: 10.32528/ellite.v2i1.759

Oshima, A. \& Hogue, A. (1997). Introduction to Academic Writing: $2^{\text {nd }}$ Edition. USA: Longman

Oshima, A. \& Hogue, A. (2006). Writing Academic English: $4^{\text {th }}$ Edition. New York: Longman

Provost, G. (1988). Beyond Style: Mastering the Finer Points of Writing. USA: Crossroad Press Rahmawati, S.M \& Susanti, Y. (2016). The Use of Transitions in the Students Argumentative Essay. Journal of English Teaching and Research. 1(2), 103112 
Stott, B. (1991). Write to the Point: and Feel Better about Your Writing:

$2^{\text {nd }} \quad$ Edition. Columbia

University Press. 